\title{
The Interface of Science and Law
}

\author{
A Challenge to the Privileging of 'Marine Biodiversity' over 'Marine \\ Environment'
}

\section{Philomène Verlaan}

\section{Introduction}

'Conscious that the problems of ocean space are interrelated and need to be considered as a whole', the third preambular paragraph to the ambitious and powerful United Nations Convention on the Law of the Sea (LOSC) ${ }^{1}$ formally recognizes in a global treaty the scientific reality of the fundamental physical interconnectedness of some 70 percent of our planet. Treaties addressing other physical parts of our world, and those of our shared 'pale blue dot'2 as a whole, would do well to adopt a similarly interconnected approach. In the absence of such treaties, the ocean and its 'Constitution,', ${ }^{3}$ the LOsc, continue to serve as a primary source of, respectively, physical and regulatory 'creative spaces' in a domain where 'connection' rather than 'separation' is the fundamental organizing principle. Against this background of physical and hence legal connectivity, this chapter considers the application of the concepts of 'boundaries' and 'frontiers', both scientifically and legally, to marine environmental protection in general and under the LOSC in particular.

Barnes and Long (chapter 1, this volume) stress the importance of distinguishing between a boundary and a frontier. A boundary, usually a formal linear construct, precisely marks a clear division between two spaces. It separates those two spaces. A frontier, albeit usually a spatial concept, has flexible dimensions; it is a zone where precise boundaries are absent. Definitively separating a frontier from its surroundings is normally not feasible. However, a frontier can be a highly 'creative space', where conventional approaches such as setting boundaries - to issues concerning that space are inappropriate, and thus offering opportunities for innovative responses. In such a creative

1 Adopted 1o December 1982, in force 16 November 1994, 1833 UNTS 3.

2 C Sagan, Pale Blue Dot: A Vision of the Human Future in Space (Headline Book Publishing, 1995).

3 TTB Koh, 'A Constitution for the Oceans' in The Law of the Sea (United Nations, 1983) xxxiii-xxxvii. 
space, meaning either a physical space or an intellectual space, or a combination of the two, the opportunity exists for the law to be developed in new ways through, for example, the utilization of scientific developments or a reprioritization of policy interests. This can be achieved through, for example, contemporary interpretation of the LOSC or developing new practices within the wider framework of the Losc.

This author considers the marine environment as perceived in the LOSC to be just such a frontier, whose precise boundaries can never be firmly fixed because of the myriad spatial, temporal, physical, geochemical and biological characteristics that require connection, not separation, for the marine environment to flourish. This view is consistent with the understanding of ocean space embodied in the preamble to the Losc quoted above. These same characteristics present States, which are required by Article 192 of the LOSC to 'protect and preserve the marine environment', with novel regulatory challenges that are currently difficult for our society to meet. Our society places a premium on boundaries (and on their apparent certainties). Nevertheless, of all the new maritime jurisdictional spaces established by the LOsc, the overall boundary-free nature of the marine environment offers particular potential for regulatory creativity, and thus also for effective protection of the marine environment.

In this chapter, the author argues that so far this potential has not been seized. Instead, by singling out only certain characteristics of the marine environment, such as its biological diversity (hereinafter biodiversity), for protection, States individually and collectively are seeking to (re)establish boundaries specifically excluded from this legal space under the LOSC. As a result, States collectively are still not meeting the marine environmental obligations imposed upon them by the LOSC, and this is further endangering even those few marine environmental components, including in particular marine biodiversity, that States have so far chosen to protect.

2

\section{Approach by the LOSC to Boundaries and Frontiers in the Marine Environment}

The LOSC does not wholly help its own case for the protection and preservation of the marine environment. Despite its initial premise of connection and an arguably implied promise to act ${ }^{4}$ accordingly, the LOSC nevertheless

4 The verb 'consider' in the third preambular paragraph does not necessarily entail, but can be interpreted to imply, a requirement to also actively 'deal with' the problems of ocean space as a whole. 
then devotes ten of its seventeen Parts to separations: i.e., methods of establishing both frontiers (e.g., high seas, the Area) and boundaries (e.g., exclusive economic zones (EEZs)) in the ocean to meet human requirements. ${ }^{5}$ But the LOSC implements its third preambular premise and redeems its implied promise most comprehensively, albeit not fully, in Part XII, entitled 'Protection and Preservation of the Marine Environment.' ${ }^{6}$ In this Part, human-devised frontiers and boundaries have either vanished (e.g., Losc Article 192: 'States have the obligation to protect and preserve the marine environment') or are subject to the LOSC's all-encompassing boundary- and frontier-free environmental imperatives derived from the biogeochemical and physical requirements of the ocean as a whole to remain healthy.

This holistic legal approach is further supported by the comprehensive definition of 'pollution of the marine environment'7 set out in Article (1)(1) (4), which also contains a non-exhaustive list of examples of pollution, and the absence of a definition of 'marine environment' in the Losc. The LOSC does provide a wide variety of non-exhaustive examples of what the 'marine environment' encompasses under its auspices. Furthermore, the marine environment of the LOSC is distinctively characterized by broad concepts of space

5 See, e.g., T Stephens and DR Rothwell, 'The LOSC Framework for Maritime Jurisdiction and Enforcement 30 Years On' in D Freestone (ed), The 1982 Law of the Sea Convention at 30: Successes, Challenges and New Agendas (Martinus Nijhoff, 2013) 27-35.

6 Part XIII on marine scientific research, another logical candidate for the interconnected approach espoused in the third preambular paragraph cited in the Introduction, recognizes and implements boundaries established by the LOSC, above ( $\mathrm{n}_{1}$ ), more than Part XII. Contrast, for example, the generalized obligations in Articles 238-244 with the boundary approach in Articles 245-246.

7 The author is baffled by the complete absence in the climate change discussions of any reference to the requirements imposed by the LOSC, above (n 1), on States to prevent, reduce and control pollution of the marine environment from any source (Art. 194; including from land, rivers and estuaries (Art. 207); and the atmosphere (Art. 212)), given the scientific consensus on the harmful effects of greenhouse gas emissions in general and on the marine environment in particular (e.g., ocean acidification, warming, deoxygenation). Greenhouse gases and their 'deleterious effects' meet the criteria for pollution of the marine environment set out in LOSC Article 1(1)(4). The requirements imposed by the LOSC on States with regard to pollution of the marine environment are far stronger than any that have emerged so far in international instruments issued under the auspices of the United Nations Framework Convention on Climate Change (UNFCCC) (adopted 9 May 1992, 1771 UNTS 107), including the UNFCCC itself. States seem to assume that dealing with greenhouse gases is legally optional. At least for the ${ }_{167}$ States, and the European Union, that are party to the LosC (as of 8 October 2020), this assumption is incorrect. This is discussed further by Bodansky, Chapter 12, this volume. See also, A Boyle, 'Law of the Sea Perspectives on Climate Change' in Freestone (ed) (2013), above (n 5), 157-164; P Verlaan, 'Geo-engineering, the Law of the Sea, and Climate Change' (2009) 3(4) Carbon and Climate Law Review 446-458. 
and of material content. ${ }^{8}$ Especially interesting are the examples of content, including: 'living resources [note absence of the qualifier 'marine'] and marine life', 'seawater' and 'amenities' [note absence of the qualifier 'marine']; 'living [and] non-living natural resources' and 'waters superjacent to the seabed'; $; 0$ marine mammals;" ${ }^{11}$ sedentary species; ${ }^{12}$ 'species associated with or dependent upon harvested species'; ${ }^{13}$ solid, liquid or gaseous mineral resources; ${ }^{14}$ flora and fauna; 15 'natural resources of the seabed and subsoil'; ${ }^{16}$ 'rare or fragile ecosystems as well as the habitat of depleted, threatened or endangered species and other forms of marine life';17 and 'alien or new species'.18

Combining elements of both space and material scope are those provisions of the LOSC that refer to the marine environment as encompassing 'related interests' ${ }^{19}$ Presumably 'related interests' include coastal interests, given that 'coastline' is invariably mentioned in the same context. It may also include fishing, which is expressly stated as an example in Article 221(1). However, the LOSC contains no other examples, and does not further define these interests. 'Related interests' is a general formulation used in the LOSC and opens the door for creative, evolutionary development of the LOsc. It potentially includes interests that are not solely environmental in nature, but also amenity interests or dependent economic interests, such as employment or tourism. This would be consistent with mechanisms on liability for vessel-source pollution that encompass a wide range of harmful effects from pollution. Some authorities have suggested that it also recognizes the relationship between the terrestrial ecosystem and the marine ecosystem. ${ }^{20}$ Such an approach is wholly

8 With regard to space, Losc, above (n $\mathrm{n}$ ) examples include the 'seabed, ocean floor, and subsoil thereof' (Art. 1(1)(1)); 'estuaries' (Art. 1(1)(4)), 'the coastline' (Arts. 142, 145, 211(1)); the territorial sea (Art. 3); internal waters (Art. 8); the EEZ (Art. 55); the continental shelf (Art. 76); the high seas (Art. 86); enclosed and semi-enclosed seas (Art. 122); the Area (Art. $1(1)(1))$; and ice-covered areas (Art. 234).

$9 \quad$ Ibid Art 1(1)(4).

$10 \quad$ Ibid Art 56(1)(a).

11 Ibid Art 65.

12 Ibid Arts 68, 77(4).

13 Ibid Art 119(b).

14 Ibid Art 133(a).

15 Ibid Art 145(b).

16 Ibid Art 194(c).

17 Ibid Art 194(5).

18 Ibid Art 196.

19 Ibid Arts 142(3), 211(1) \& (7), 220(6), 221(1).

20 See K Bartenstein, 'Article 211 Pollution from Vessels' in A Proelss (ed), United Nations Convention on the Law of the Sea. A Commentary (Beck/Hart/Nomos, 2017) 1427, para 13; see also, e.g., LOSC, above (n 1), Arts 194(1) ('pollution of the marine environment from 
consistent with argument in favour of an integrated, holistic approach to environmental protection being advanced in this chapter.

Finally, the marine environment as envisioned under the LOSC possesses an 'ecological balance', interference with which must be prevented, reduced and controlled. ${ }^{21}$ Ice-covered areas also possess an 'ecological balance', and here States must prevent, reduce and control 'pollution of the marine environment [that] could cause major harm to or irreversible disturbance of the ecological balance. ${ }^{22}$ In this complex Article it is not entirely clear whether the ecological balance criterion applies only to ice-covered areas or also, as in Article 145(a), to the marine environment as a whole. However, both Articles are adduced here to highlight the addition of a third element, 'ecological balance', to this consideration of constituents of frontiers and boundaries under the Losc. This third element is an intrinsic characteristic that has not only spatial and content aspects, but is also a feature that transcends traditional frontier and boundary concepts.

Arguably, both of these intriguing phrases - 'related interests' and 'ecological balance' - further expand the frontiers and boundaries of the concept of 'marine environment' under the LOSC into a new creative space for regulatory action. Neither has yet been judicially interpreted, which leaves open such regulatory possibilities for the time being.

Part XII offers examples of marine areas that could still perhaps be considered as entailing individual environmental frontiers or boundaries within ocean space - as distinguished from the marine environment generally namely, 'rare or fragile ecosystems as well as the habitat of depleted, threatened or endangered species and other forms of marine life. ${ }^{23}$ However, these examples are clearly placed in the context of the wider marine environmental measures that States must take to protect and preserve the marine environment under Part XII. It is clear under the LOSC that protecting these habitats and ecosystems is both necessary and mandatory but insufficient to protect the marine environment. Their protection cannot substitute for, but must complement, other forms of protection. These include all the other requisite marine

any source'), 194(2) (activities under the jurisdiction or control of States), 195 (duty not to transfer damage or hazards from one area to another or to transform one type of pollution into another), 207 (pollution from land-based sources) and 212 (pollution from or through the atmosphere), further discussed below.

21 LOSC, above (n 1), Art 145(a).

22 Ibid Art 234.

23 Ibid Art 194(5). 
environmental protection measures set out in the LOSC. ${ }^{24}$ They are all part of the same overarching boundary- and frontier-free environmental protection system set up under the LOSC. In other words, the LOSC situates the selective protection of certain environmental components within the protection of the marine environment as a whole. Respecting such a holistic approach is clearly in line with the spirit of the LOSC as set out in its preamble.

A similar approach of identifying specific components of the marine environment for protection, but setting them clearly in the context of the marine environment as a whole, also occurs in Part XI which deals with the Area. It requires measures to protect organisms that are not only found in the Area, that is, 'for, inter alia: ... the prevention of damage to flora and fauna of the marine environment ${ }^{25}$ This distinction for flora and fauna is particularly telling in that the self-same clause also requires 'the protection and conservation of natural resources of the Area. ${ }^{26}$

As pointed out above, in this frontier- and boundary-free concept of the marine environment offered by the LOSC, the requirement in Part XI 'for the prevention, reduction and control of ... interference with the ecological balance of the marine environment ${ }^{27}$ is the most ambitious and most difficult concept to define and implement, both legally and scientifically. As with flora and fauna, in Part XI this requirement sets no boundary limitation to the marine environment of the Area. With regard to Part XII, where the ecological balance criterion appears only in the complex Article 234 on ice-covered areas (see discussion above), even if the criterion there is judicially interpreted to apply only to ice-covered areas, this will not facilitate its definition and implementation in that specific context.

If the LOSC sets any boundaries at all on the marine environment, it is arguable that the boundaries are planetary, that is, defined by the constraints of the 'pale blue dot' itself. The LOSC achieves this by bringing within its purview the adverse effects on the marine environment from activities on land and in the atmosphere. ${ }^{28}$ Traditional geographic land and air frontiers, as well as human-devised maritime boundaries (whether formally delimited or not), have always been physically irrelevant as far as the marine environment is concerned. To give a few examples, this is illustrated by the adverse effects on the

24 Ibid: 'The measures taken in accordance with this Part shall include those necessary to protect and preserve rare ... life'.

25 Ibid Art 145(b) (emphasis added).

26 Ibid (emphasis added).

27 Ibid Arts 145(a), 234 (emphasis added).

28 See respectively, ibid Arts 207 and 212. 
marine environment of carbon dioxide $\left(\mathrm{CO}_{2}\right), \mathrm{CFC} \mathrm{s},{ }^{29}$ and so-called black carbon (soot) emissions into the air, even from sources located far inland. ${ }^{30}$ Also important are the provisions on the introduction into the marine environment of various harmful substances, even when delivered via rivers (specifically referred to in Article 207(1)), where the input sources may be far upstream. ${ }^{31}$

Furthermore, the LOSC subjects all of ocean space, including the jurisdictional areas set out therein, to Part XII. Nowhere in the LOSC is Part XII explicitly or implicitly made inapplicable to any part of ocean space. This includes the high seas (Part VII), where Part XII obligations are left applicable to the high seas 'freedoms', including marine scientific research. ${ }^{32}$ The LOSC also subjects any activity (again including marine scientific research in LOSC Part XIII) ${ }^{33}$ or incident (e.g., Part XII, Article 194), no matter where it occurs, including on the high seas, ${ }^{34}$ to Part XII, whenever the marine environment is or may be adversely affected thereby. Thus, human-devised frontiers and boundaries are almost wholly immaterial under the LOSC where the legal applicability of the marine environmental protection requirements of the LOSC is concerned. ${ }^{35}$ These include jurisdictional arrangements (e.g., a 'legal' continental shelf, high seas, EEZ, territorial sea, the Area) assigning to States various competences and requirements to act. Put another way, the jurisdictional arrangements should not be regarded as obstacles to the application of general obligations to protect the marine environment.

29 Chlorofluorocarbons.

30 See, e.g., Intergovernmental Panel on Climate Change (IPCC), Fifth Assessment Report (4 volumes) (2014), https://www.ipcc.ch/assessment-report/ar5/; accessed 5 July 2018.

31 See, e.g., H Kremer and R Ramachandran, Land-Based Pollution Sources: A Global Synopsis of Land-Based Pollution Sources-Science and Transboundary Management (United Nations University-Institute for Water, Environment and Health, 2012), https://collections.unu.edu/eserv/UNU:2673/Land-Based-Pollution-Sources-Synopsis-Report.pdf; accessed 8 October 2020 .

32 'Freedom of the high seas is exercised under the conditions laid down by this Convention and by other rules of international law': Losc, above (n 1), Art 87(1). See also, P Verlaan, 'Marine Scientific Research: Its Potential Contribution to Achieving Responsible High Seas Governance' in Freestone (ed) (2013), above (n 5), 131-138.

Verlaan, ibid.

34 Ibid.

35 It is worth noting that the International Court of Justice (ICJ) has taken a very expansive approach to defining the environment. See, for example, Legality of the Threat or Use of Nuclear Weapons, Advisory Opinion, (1996) ICJ Reports, p 226, where it stated: 'The environment is not an abstraction but represents the living space, the quality of life and the very health of human beings, including generations unborn' (para 29). Although the ICJ did not categorise these as obligations of absolute restraint, this was in the context of selfdefence, rather than other environmental priorities. 
The LOSC also sets out certain human-devised frontier/boundary-based legal nuances related to implementation and enforcement of their marine environmental responsibilities by States. Some of these boundaries/frontiers concern State 'jurisdiction or control' and may also differ depending on a given State's flag, port or coastal State status. ${ }^{36}$

However, it is important to note that elsewhere in Part XII the frontier/ boundary concept entailed in adding the adjective 'marine' in the context of environmental protection disappears. All of the environment - not only the marine environment - belonging to 'other States', as well as those 'other States' themselves, must be protected from polluting activities by States. ${ }^{37}$ Nor is it permitted under the LOsC for such pollution to 'spread beyond the areas where they exercise sovereign rights in accordance with this Convention'. ${ }^{38}$ Article 195 not only reinforces the obligation of Article 194(2) but, in its reference to 'areas' and 'types of pollution', also arguably strengthens its own applicability to more than only the marine environment. ${ }^{39}$ Thus this chapter also argues that to achieve the purpose of the LOSC to protect the marine environment entails action on non-marine activities if the consequences adversely affect the marine environment (for examples of such 'deleterious effects', see LOSC Article 1(1)(4)). This necessarily implies the need for non-marine preventive, protective and control measures on non-marine activities. All this further renders a human-derived 'marine' frontier/boundary approach for marine environmental protection purposes irrelevant from the perspective of taking effective protection and preservation measures.

It is sobering to consider how these two wholly unqualified legal requirements have been ignored in the context of State action so far with regard to, for example, greenhouse gas emissions ${ }^{40}$ and $\mathrm{CO}_{2}$ sequestration under the

36 For example, 'under their jurisdiction and control' (e.g., LOSC, above (n 1), Arts 194(2), 196(1)); 'flying their flag or of their registry or operating under their authority' (e.g., Arts 209(2), 211(2)), 217 (flag); 218 (port); 220 (coastal)). See also, e.g., Stephens and Rothwell, above ( $\left.\mathrm{n}_{5}\right)$.

37 Ibid Art 194(2): 'States shall take all measures necessary to ensure that activities under their jurisdiction or control are so conducted as not to cause damage by pollution to other States and their environment, and that pollution arising from incidents or activities under their jurisdiction or control does not spread beyond the areas where they exercise sovereign rights in accordance with this Convention' (emphasis added).

38 Ibid. These areas are not limited to the oceans, but include the land (Art 207) and the atmosphere (Art 212).

39 Ibid, Art 195: 'In taking measures to prevent, reduce and control pollution of the marine environment, States shall act so as not to transfer, directly or indirectly, damage or hazards from one area to another or transform one type of pollution into another'. 
Protocol to the London Convention. ${ }^{41}$ The Protocol was amended twice in this context: first, to permit the disposal of $\mathrm{CO}_{2}$ in sub-seabed geological formations, which would otherwise have been prohibited under Protocol Annex 1, ${ }^{42}$ and second, its transboundary transport for this purpose, ${ }^{43}$ which would otherwise have been prohibited under London Protocol Article 3(3) (which echoes LOSC Article 195), and Article 6, which prohibits the export of wastes or other matter to other countries for dumping or incineration at sea, and is an application of Article 194(2) of the LOSC. This author has argued elsewhere that these amendments to the Protocol are incompatible with both instruments. ${ }^{44}$

Nowhere in the LOSC are the States' primary and unqualified responsibilities under Article 192 to protect and preserve the marine environment legally curtailed on the basis of either a frontier or a boundary in or imposed upon the ocean. This is the case regardless of whether these frontiers or boundaries are scientifically recognized (such as a current system, an upwelling zone, a subduction zone, a euphotic zone, a thermocline, an oxygen-minimum zone, a geological continental shelf) or human-devised (see examples of jurisdictional arrangements given above). Thus, under the LOsc the marine environment of the ocean becomes a 'creative space' wherein the natural and artificial frontiers and boundaries are conceptually and physically transcended. Here is where the integrated protection of organisms and species and habitats and ecosystems must occur, both scientifically and legally, within a mandatory regulatory structure of protection. The inspiring potential of this creative space is to enable and facilitate this unified approach to environmental protection. In summary, the LOSC requires the marine environment in its entirety to be protected, not just parts of it.

41 Convention on the Prevention of Marine Pollution by Dumping of Wastes and Other Matter (London Convention), adopted 29 December 1972, in force 30 August 1975, 1046 UNTS 12O; 1996 London Protocol, adopted 7 November 1996, in force 24 March 2006, [2006] ATS 11.

IMO, Report of the 28th Consultative Meeting of Contracting Parties to the 1972 [London Convention] and the 1st Meeting of Contracting Parties to the 1996 London Protocol, IMO Doc LC28/15, 6 December 2006, paras 66-109 and Annex 6. The amendment entered into force on 10 February 2007.

43 IMO, Report of the 31st Consultative Meeting of Contracting Parties to the 1972 [London Convention] and the 4th Meeting of Contracting Parties to the 1996 London Protocol, IMO Doc LC28/15, 30 November 2009, paras 5.1-5.32 and Annex 5. This amendment is not yet in force.

Verlaan (2009), above (n 7), 457 . 
Rather than seizing the challenging but fascinating and unique opportunity to develop the required integrated regulations for the distinctive 'creative space' offered by the huge boundary/frontier-free marine environment as envisaged by the LOSC, the international community has proposed and in some cases introduced regulations for a suite of what are apparently intended to be biologyderived frontiers and boundaries in the ocean. These include marine protected areas (MPAs) established by individual and groups of States, ${ }^{45}$ the International Maritime Organization's (IMO) Particularly Sensitive Sea Areas (PSSAs), ${ }^{46}$ the United Nations Food and Agriculture Organization's (FAO) vulnerable marine ecosystems (VMEs), ${ }^{47}$ and the Convention on Biological Diversity's (CBD) Ecologically or Biologically Significant Marine Areas (EBSAs). ${ }^{48}$ Their boundaries and frontiers are biologically controversial, at least among scientists, do not usually overlap, and seem to be primarily set to meet the objectives of their proponent States and organizations, rather than specifically complying with the marine environmental protection requirements of the LOSC.

A central organizing criterion of MPAs, PSSAs, VMEs and EBSAs is the concept of the 'biodiversity hotspot'. These terms are not found in the LOSC and external definitions vary, which is not helpful in developing a legal regime around the concept. For the purposes of this chapter, the working definition refers to areas that are particularly rich (diverse) in species and high in endemism (i.e., hosting species found nowhere else), ${ }^{49}$ and are therefore considered to merit special protection. This approach adds further boundary and frontier complexities to proposals for protecting the marine environment; for example, diversity and endemism are not easily measured within narrow spatial frameworks, and the vital temporal aspect is wholly ignored with this approach. As explained in section 5 below, the hotspot approach is unlikely to assist in and

45 For an up-to-date list and descriptions, see Marine Conservation Institute, 'Atlas of Marine Protection', http://www.mpatlas.org/map/mpas/; accessed 10 July 2018.

46 For an up-to-date list and descriptions, see Imo, 'Particularly Sensitive Sea Areas', http://www.imo.org/en/OurWork/Environment/PSSAs/Pages/Default.aspx; accessed 2 July 2018.

47 For an up-to-date list and descriptions, see FAO, 'Vulnerable Marine Ecosystems', http:// www.fao.org/in-action/vulnerable-marine-ecosystems/en/; accessed 2 July 2018.

48 For an up-to-date list and descriptions, see Convention on Biological Diversity (СвD), 'Ecologically or Biologically Significant Marine Areas', https://www.cbd.int/ebsa/; accessed 2 July 2018.

49 ER Selig, WR Turner, S Troëng et al., 'Global Priorities for Marine Biodiversity Conservation' (2014) 9(1) PLoS ONE e82898, https://doi.org/10.1371/journal.pone.oo82898. 
may indeed hamper achieving this environmental protective objective under both the LOSC and the suite of State and intergovernmental marine environmental regulatory systems listed above.

Currently occupying much of the international community's attention for marine environmental issues is the decision by the United Nations General Assembly (UNGA) to develop an international legally binding instrument(ILBI) under the LOSC on the conservation and sustainable use of marine biological diversity of areas beyond national jurisdiction (ABNJ), (hereinafter referred to as the ввNJ negotiations). ${ }^{50}$ An organizational session was held 16-18 April 2018, in New York. The third session of the Intergovernmental Conference to develop the ILBI was held 19-30 August 2019, in New York.

Particularly striking, in the context of the present discussion, is the introduction of both a human-devised (i.e., ABNJ) and a biological boundary/ frontier (i.e., marine biodiversity) to a problem (i.e., protection of the marine environment of ocean space as a whole). One origin of this situation can be traced to the increasing focus by the international community on biodiversity and ecosystems, rather than the environment as a whole, in the international discourse on conservation. ${ }^{51}$ Here, maintaining a conceptual boundary - not a frontier - is useful. This is because biodiversity and ecosystems must not be conflated. They play distinct but highly interactive roles, as illustrated by their definitions in the Convention on Biological Diversity. ${ }^{52}$ The свD defines biodiversity as 'the variability among living organisms from all sources including, inter alia, terrestrial, marine and other aquatic ecosystems and the ecological complexes of which they are part; this includes diversity between species, among species and of ecosystems' (Article 2). The СвD defines 'ecosystem' as 'a dynamic complex of plant, animal and micro-organism communities and their non-living environment interacting as a functional unit' (Article 2). ${ }^{53}$

$5^{\circ}$ UN General Assembly, Resolution A/REs/72/249: International legally binding instrument under the United Nations Convention on the Law of the Sea on the conservation and sustainable use of marine biological diversity of areas beyond national jurisdiction, adopted 24 December 2017 (ввNJ negotiations).

51 For a general historical overview, see JL de Andrade Franco, 'The Concept of Biodiversity and the History of Conservation Biology: From Wilderness Preservation to Biodiversity Conservation' (2013) 32(2) História 21-48, DOI:10.159o/So101-90742013000200003. For an overview focused on the ocean, see EA Norse (ed), Global Marine Biological Diversity: A Strategy for Building Conservation into Decision-Making (Island Press, 1993).

$5^{2}$ Adopted 5 June 1992, in force 29 December 1993, 1760 UNTS 79.

53 Boyle, above $(\mathrm{n} 7), 158$, remarks that the СвD can be cited to support the view that LOSC 'Part XII can readily be interpreted to cover protection of marine biodiversity in general, and conservation of coral reefs in particular'. 
Albeit not ideal, these definitions suffice for this chapter insofar as for biodiversity they highlight variability, and for ecosystems they emphasize interactions, demonstrating that the central operative element is active, not passive, for both.

Scientists usually consider biodiversity to be both an attribute and a component of ecosystems. A variety of ecosystems is included in the concept of biodiversity. Biodiversity provides options for organisms to respond to natural and anthropogenic environmental challenges by at least maintaining (if not enhancing) their variability. For optimal functioning, biodiversity requires healthy ecosystems and vice-versa. Ecosystems too require biodiversity for their constituent communities and their interactions to operate effectively. Effective operation includes the ability for ecosystems to respond constructively to both environmental challenges and changes. Maintenance of biodiversity is essential to ecosystem stability. Loss of biodiversity can temporarily or permanently move an ecosystem into a different set of biogeochemical conditions, which may disrupt or reduce effective operation of the ecosystem. ${ }^{54}$

The distinctively dynamic and interactive nature of biodiversity and ecosystems presents a formidable challenge to achieving an environmentally and commercially responsible use of our planet. Unfortunately, this challenge is made even more difficult in that the definitions lack an operative context, at least in the CBD. ${ }^{55}$ The CBD's ecosystem definition contains but a single and rather cursory reference to the 'non-living environment'. Hence one might not unreasonably infer that, in the CBD's view of the natural world, not only do ecosystems and biodiversity seem to exist independently of their greater surroundings, that is, the natural world in which they are located and within which they must function, but also that they can be protected independently from and regardless of the health of those surroundings as well.

The following section briefly describes why this view does not correctly reflect the realities of marine ecosystems and marine biodiversity, and hence why a sole focus on protecting marine biodiversity will not protect it adequately, if at all. ${ }^{56}$ It also explains why great caution is required when a

54 See, e.g., EO Wilson and FM Peter (eds), Biodiversity (National Academies Press, 1988); B Cardinale, 'Impacts of Biodiversity Loss' (2012) 336(6o81) Science 552-553, DOI: 10.1126/ science.1222102.

55 See also, Gullett, Chapter 14, this volume, who makes a similar argument regarding the precautionary approach/principle.

56 This argument is likely to be applicable to terrestrial biodiversity and ecosystems also; however, the terrestrial environment is beyond the scope of this chapter and this remark is offered here only as a cautionary note. 
scientific concept - such as biodiversity - is succinctly expressed in a deceptively simple and accessible phrase and adopted by a non-specialist community. Elegant articulation can mask the complexity and scientific uncertainty of a concept. This risks its premature and/or unsuitable application in inappropriate contexts, such as becoming the subject and object of legally binding obligations, and it can lead to unforeseen and not necessarily desirable consequences. The latter can include counteracting the very objective for which the concept is invoked and deployed.

\section{4}

\section{Marine Ecosystems and Marine Biodiversity}

\subsection{Static and Mobile Marine Ecosystems}

Marine ecosystems can be broadly divided into 'static' ecosystems, i.e., those more or less fixed to or closely associated with a solid surface, ${ }^{57}$ and 'mobile' ecosystems, that is, those found in the marine environment as a functioning unit unattached to any fixed substrate.

\subsubsection{Static Marine Ecosystems}

Progressing, roughly speaking, from the coast to offshore and from shallow water to deep water, static ecosystems include: estuaries, wetlands, mangroves, beaches, seagrass beds, kelp forests, coral reefs, sponge fields, cold-water coral 'reefs', hydrothermal vents, cold seeps, mud volcanoes, continental shelves and slopes, submarine canyons, seamounts, abyssal hills, abyssal plains, and trenches. These static ecosystems often straddle or fit poorly, if at all, within human-derived boundaries, including the different jurisdictional zones set out in the LOSC. For example, 'legal' continental shelves can span territorial seas and the EEz and, if extended, adjoin the Area, itself another legal construct functioning as a boundary/frontier. Activities on the high seas and States exercising their high seas freedoms can affect ecosystems in all jurisdictional zones. ${ }^{58}$ Ecosystems such as cold-water coral reefs and hydrothermal vent

57 Note that 'more or less' is a necessary qualifier, because many 'static' ecosystems, such as beaches, wetlands, estuaries and mangrove swamps, are in fact highly dynamic and even mobile to a certain extent.

$5^{8}$ See, e.g., P Verlaan, 'Experimental Activities that Intentionally Perturb the Marine Environment: Implications for the Marine Environmental Protection and Marine Scientific Research Provisions of the 1982 UN Convention on the Law of the Sea' (2007) 31(2) Marine Policy 210-216. For a description and analysis of an innovative, creative and environmentally integrated response under international law to two relatively new 
systems can span EEZ and high seas boundaries. Some static ecosystems, such as wetlands and mangrove swamps, test conventional concepts of land and sea boundaries.

\subsubsection{Mobile Marine Ecosystems}

Mobile (also called 'pelagic') ecosystems are quite common in the marine environment, especially in the open ocean. They are also essential to maintaining marine biodiversity. Mobile ecosystems consist of assemblages of species and processes found in the water-column as functioning units unattached to any fixed substrate. The Sargasso Sea, located in a mid-ocean gyre bounded by currents and with no land boundaries, is a well-known example. ${ }^{59}$ They often occur in association with hydrographic features, such as upwelling (where deep, dense, cool, usually nutrient-rich water moves up and replaces surface water drawn away by the wind), fronts (an abbreviation of 'frontier': where two different water masses meet), eddies (rotating water masses; they can also be thought of as circular fronts) and gyres (large systems of rotating ocean currents; yet another frontier). These features can be persistent or ephemeral, and occur on a variety of temporal and spatial scales. ${ }^{60}$ An important, but as

marine activities, see P Verlaan, 'New Regulation of Marine Geo-engineering and Ocean Fertilization' (2013) 28(4) International Journal of Marine and Coastal Law 729-736.

59 See, e.g., Sargasso Sea Commission, 'About the Sargasso Sea', http://www.sargassoseacommission.org/about-the-sargasso-sea/oceanographic-characteristics; accessed 1 July 2018.

60 See, e.g., A Longhurst, Ecological Geography of the Sea (Academic Press, 1998); A Belgrano, S Batten and PC Reid, 'Pelagic Ecosystems', in Encyclopedia of Biodiversity (2nd edn, Elsevier, 2013) 683-691. The 'mobile ecosystem' concept offers scope to include, for example, fishing stocks with their associated species; see Losc, above (n 1), Article 61(3) and (4) on, respectively, 'interdependence of stocks' and 'associated or dependent species' in the context of the conservation of living resources, as well as the deep scattering layer. The latter is a diurnally mobile $\sim 5^{\mathrm{O}-200} \mathrm{~m}$-thick stratum of organisms found near the surface at night and several hundred metres deeper during the day. On a smaller, but no less important, temporal and spatial scale are the 'cleaner stations' on coral reefs. A 'nonliving' example (cf. discussion of the CBD's neglect of this environmental aspect in section 5 (supra) of this chapter) is the sound channel, found in open ocean mid-latitudes at around $1000 \mathrm{~m}$ water depth to near the surface in polar oceans, which greatly extends the range over which underwater sound can be transmitted. Other sound channels also exist under suitable physical conditions. For a discussion of their environmental significance and the need for their protection under the Losc, see Verlaan (2007), above $\left(\mathrm{n} 5^{8}\right)$. Acoustic pollution of the marine environment, exacerbated by ocean acidification, is a growing threat to both marine biodiversity and marine ecosystems which has not yet been meaningfully addressed in any legally binding context, despite its inclusion-as a form of 'energy' - in the definition of pollution in Losc Article 1(1)(4), which must be prevented, reduced and controlled (LOSC, Art 194). 
yet insufficiently - for marine environmental purposes - recognized mobile marine ecosystem is the sea-surface micro-layer. ${ }^{61}$

The marine environment also hosts mobile water-column realms that are essential to both biodiversity and ecosystem functions and mechanisms, but that do not fit neatly into either the biodiversity or the ecosystem concepts. These realms include areas where species aggregate to breed, spawn, feed, rest, seek refuge or just normally live in large numbers (school), ${ }^{62}$ or migrate. It is crucial to maintain physical connectivity for marine communities in the marine environment because species need to be able to move to accomplish these stages in their life cycle that are essential to their survival. ${ }^{63}$ Migration routes and bottlenecks, which frequently involve straits and passages that are also important to other ocean activities, such as maritime transport, can fall into both static and mobile categories. These examples further illustrate the futility of attempts to apply human-derived frontier/boundary concepts to marine environmental protection.

Mobile ecosystems and realms are often driven by physical processes that can combine to provide especially favourable circumstances for the activities they host, in that they function to enrich, concentrate and retain various species. These are often called 'ocean triad' areas, which can serve as a basis for developing open ocean conservation areas. ${ }^{64}$ Thus the existence of mobile ecosystems in the marine environment challenges our boundary- and frontierfocused modes of thinking.

In summary, marine ecosystems, both mobile and static, are many and varied, they operate on a wide range of temporal and spatial scales, and they are all essential for maintaining marine biodiversity.

61 O Wurl, W Ekau, WM Landing and CJ Zappa, 'Sea Surface Microlayer in a Changing Ocean-A Perspective' (2017) 5 Elementa: Science of the Anthropocene 31, DOI:10.1525/ elementa.228; M Cunliffe, A Engel, S Frka et al., 'Sea Surface Microlayers: A Unified Physicochemical and Biological Perspective of the Air-Ocean Interface' (2012) 109 Progress in Oceanography 104-116.

62 See, e.g., Longhurst, above (n 6o); Belgrano et al., above (n 6o); M Wurtz, Mediterranean Pelagic Habitat Protection (IUCN, 2007).

63 See, e.g., M Hidalgo, DM Kaplan, LA Kerr et al., 'Advancing the Link between Ocean Connectivity, Ecological Function and Management Challenges' (2017) 74(6) ICES Journal of Marine Science 1702-1707; RK Cowen, G Gawarkiewicz, J Pineda et al., 'Population Connectivity in Marine Systems: An Overview' (2007) 20(3) Oceanography 14-21; G Jones, M Srinivasan and G Almany, 'Population Connectivity and Conservation of Marine Biodiversity' (2007) 20(3) Oceanography 100-111.

Wurtz (2007), above (n 62). 
It is probably impossible to single out specific 'biodiversity hotspots' - that is, so-called key areas of the marine environment - for protection. This is because these areas are all important to some species at some point in their life cycle. Parts of the marine environment can be protected from direct resource extraction and other uses, and from certain very physical forms of habitat destruction and degradation. Environmentally this is helpful, but who decides what is 'key'? In whose terms and on whose spatial and temporal scales are these decisions considered? Those of humans or of marine species and ecosystems? ${ }^{65}$

Marine species and ecosystems cannot be protected from the effects of, for example, acidification, warming, oxygen depletion, noxious substances and noise pervading the marine environment by imposing human-derived boundaries. These effects all lead, at the very least, to habitat degradation. The Свр defines habitat as 'the place or type of site where an organism or population naturally occurs'. This is not incorrect, but facilitates boundary-based strategies. The 'hotspot' approach also does not help any of the species (which includes most marine species) which must disperse (e.g., as larvae) or migrate (e.g., as juveniles or adults) at some point in their life cycle. The habitats they migrate to, and the corridors between the habitats, must also be hospitable. Habitats, including corridors, are crucial parts of ecosystems, and they all form part of the marine environment. Thus degradation of either, let alone both, of the former inevitably harms the latter (and vice-versa).

Furthermore, all of the ecosystems listed above, and others not included here, as well as marine habitats, have their own distinctive biodiversity, including endemics (i.e., species found only at one restricted location). For example, two adjacent seamounts can each have species that are peculiar only to it, and not found on its neighbour. Average levels of endemism on seamounts are probably at least 15 percent and have been documented as being as high as $30-50$ percent in some regions. ${ }^{66}$

65 For discussion of these and other problems with the 'hotspot' approach to conservation, see, e.g., Selig et al., above (n 49); CD Orme, RG Davies, M Burgess et al., 'Global Hotspots of Species Richness Are Not Congruent with Endemism or Threat' (2005) 436(7053) Nature 1016-1019; P Kareiva and M Marvier, 'Conserving Biodiversity Coldspots' (2003) 91 American Scientist 344-351.

66 P Verlaan, A Rogers and G Preston, Anthropogenic Threats to Seamount Ecosystems and Biodiversity (IUCN, 2012); G Stone, L Madin, K Stocks et al., 'Seamount Biodiversity, Exploitation and Conservation' in L Glover and S Earle (eds), Defying Ocean's End: An Agenda for Action (Island Press, 2004) 43-70. 
Marine ecosystems and habitats and their associated biodiversity form essential parts of the marine environment and together they extend throughout ocean space. Therefore, marine biodiversity cannot be adequately protected by slicing up ocean space into parts that are protected and parts that are not.

Throughout the LOSC, the marine environment as a whole is the fundamental frame of reference within which other, sometimes more specific requirements (e.g., 'to protect and preserve rare or fragile ecosystems as well as the habitat of depleted, threatened or endangered species and other forms of marine life') ${ }^{67}$ are situated. The drafters of the LOSC also brought the two conventionally 'non-marine' (i.e., the conventional 'frontiers' of the atmosphere and the land, as stated above) parts of our planet within the full authority of the LOSC by means of the potential or actual adverse effects on the marine environment of activities conducted there. All activities within the scope of the LOsc, including the so-called high seas freedoms, are specifically made subject to the LOSC's largely unqualified provisions to protect the marine environment. ${ }^{68}$ Thus the LosC remains the most comprehensive and powerful international treaty concluded to date by the international community to address conservation and environmental issues. ${ }^{69}$

The drafters of the LOSC, firmly grounded in the physical realities of the natural world in general and the extensive interconnectedness of the marine world in particular, expressed these realities in the third paragraph of the Preamble to the LOSC quoted in the Introduction to this chapter. They then adopted a broad and scientifically justifiable approach to marine conservation by requiring the protection and preservation of the marine environment, not just of parts of it, in Article 192.

67 The author has searched, so far in vain, for a scientific analysis of whether, and if so, how, this requirement, and the one relating to the ecological balance of the marine environment, would be more amenable to definition and implementation and therefore more useful in protecting the marine environment as required by the LOSC than the marine biodiversity hotspot approach. This analysis would have the additional utility of initiating a scientific basis for construing the LOsc's own legally binding language, should these clauses of the LOSC be submitted to judicial interpretation.

68 The general absence of qualifications and other 'weakening language' in the Losc with regard to marine environmental protection is particularly important because another problem with implementing the $\mathrm{CBD}$ is that it does not protect biodiversity without qualification. For a discussion see Verlaan (2009), above (n 7), 454; see also P Birnie, A Boyle and C Redgwell, International Law and the Environment (3rd ed, Oxford University Press, 2009), who also note this weakness in the CBD.

69 Birnie et al., above (n 68), remark that 'any meaningful attempt to regulate marine biodiversity depends on [LOSC] parties, not CBD parties'. 
Protection of the marine environment, and thus marine biodiversity and marine ecosystems, requires tackling the causes of their threats. The LOSC requires prevention, reduction and control, in that order (cf. Article 194). Consider the scale of the human footprint on the environment; it is now rather more akin to an immense, hobnailed, seven-league boot. Population growth alone already ensures that the boot will not decrease in size, in that the concomitant human activities will increase. 'Tackling' these causes therefore entails at least reducing, and preferably preventing and eliminating, the causes altogether. This requires reviewing human activities in terms of their potential adverse effects on the marine environment. This should also be done in terms of potential adverse effects on the terrestrial environment, but unlike the marine environment, the terrestrial and atmospheric environments lack a similarly overarching treaty unequivocally mandating their protection.

It is always easier and much less expensive to prevent damage than to fix it, even assuming that the damage can be fixed. Note again, as stated elsewhere, that the LOSC requires prevention, reduction and control, in that order. Just as human society is being reluctantly dragged towards the not just inconvenient, ${ }^{70}$ but inexorable truth that global warming requires us to stop $\mathrm{CO}_{2}$ emissions at source, other human activities will have to do the same for their adverse environmental effects - at least on the marine environment. This means, for example, that 'operational discharges' into the marine environment from vessels and land-based sources of pollution, such as plastics, ${ }^{71}$ must be prevented, not just reduced and controlled. ${ }^{72}$ These boundaries must be effaced.

Attempting to protect marine biodiversity and marine ecosystems, no matter how they are defined or where they are located (e.g., within or outside national jurisdiction, within or outside MPAS, PSSAS, VMES, EBSAS) is futile, if at the same time the international community does not take the necessary action required under the LOSC to protect from pollution the marine environment wherein this marine biodiversity and these marine ecosystems are found. ${ }^{73}$ The UNGA's well-meant BвNJ negotiations, and all the

70 A Gore, (Screenplay) An Inconvenient Truth (2006) Documentary film, ih 58m; Director: Davis Guggenheim.

71 See Oral, chapter 11, this volume.

72 P Verlaan, 'Overview of Opportunities under the Law of the Sea to Improve Marine Environmental Conservation Affected by Maritime Traffic' in N Oral and F Simard (eds), Maritime Traffic Effects on Biodiversity in the Mediterranean Sea, vol 2 (IUCN Centre for Mediterranean Cooperation, 2008) 9-48.

73 This is defined in the LOSC, above (n 1), Article 1(1)(4) as the actual or potential adverse effects of 'the introduction by man, directly or indirectly, of substances or energy into the marine environment, including estuaries, which results or is likely to result in such 
other equally well-meant efforts to pick and choose bits of the ocean and its biology to protect (e.g., MPAs, PSSAs, VME s, EBSAs) are ultimately doomed to failure from a marine environmental perspective if the pervasive pollution of the marine environment is not also robustly fought as well. States and international institutions should reconsider this scientifically unsound and functionally unimplementable boundary- and frontier-based approach to marine governance. They should focus less on marine biodiversity and a limited, arbitrary set of ecosystems and shift their focus to protecting the marine environment as a whole. Boundary- and frontier-free marine environmental protection is clearly and specifically required by the LOSC, without exceptions or qualifications.

The continuing absence of any serious, concerted and integrated implementation and enforcement by the States Parties to the LOSC of its marine environmental requirements in areas within national jurisdiction, let alone in $\mathrm{ABNJ}$, risks exposing the States Parties to complaints that they are not meeting their legally binding obligations under the LOSC. ${ }^{74}$ It is therefore particularly ironic and paradoxical that the UNGA chose to explore its laudable - albeit far too restricted - objective in the context of a spatially and conceptually limited implementation instrument for the LOSC, which demands the most comprehensive approach to marine environmental protection available in international law to date. Therefore, for the reasons given above, the current approach of the BвNJ negotiations risks an outcome that is unlikely to satisfy the requirements of its governing instrument, and even risks at the very least running counter to its spirit, if not its letter, with regard to protection and preservation of the marine environment. Such a result will be to the detriment to all of us and our 'pale blue dot'.

deleterious effects as harm to living resources and marine life, hazards to human health, hindrance to marine activities, including fishing and other legitimate uses of the sea, impairment of quality for use of sea water and reduction of amenities' (note the precautionary language: 'results or is likely to result').

74 This issue merits examination by the States Parties to the LOSC (SPLOS). They meet annually. The agenda for their meetings has, alas, so far lacked the vision, ambition and inspiration that characterize their governing instrument. The reports of the 29 SPLOS meetings held up to October 2020 are available at http://www.un.org/depts/los/meeting states_parties/SPLOS_documents.htm; accessed 8 October 2020. The perceived need for the BBNJ negotiations is arguably not unrelated to the apparent lack of concern for the marine environment evinced by the current SPLOS process. 
The true environmental challenge and both the first and the 'final' ${ }^{\prime} 5$ frontier is for us humans to manage ourselves. It is unwise to imagine that we can manage marine ecosystems, or marine biodiversity or even the marine environment itself, or even all three together, let alone choose and prioritize between them. ${ }^{76}$ Some twenty-five hundred years ago $(\sim 5 \mathrm{OO}$ BCE $)$ the Greeks considered this type of thinking to be hubristic. Their stories, ${ }^{77}$ plays $^{78}$ and poetry ${ }^{79}$ that addressed the pitfalls of hubris were all tragedies. Not a single one ended well for anyone involved. Marine ecosystems and marine biodiversity and their marine environment can manage themselves perfectly well without us. This author surmises that they would probably do so even better if we were not around. Nevertheless, as long as we remain around, we must consider how best to manage the causes of our 'deleterious effects' rather than the recipient locations, communities and organisms of these effects. Given the poor record of past attempts to manage ourselves with regard to environmental issues, new approaches are needed.

One suggested new approach is to change the current conceptual and hubristic misnomer of managing 'marine ecosystems', 'marine biodiversity', and even the 'marine environment' itself. The time is ripe to graduate from the 'ecosystem approach to management' to the 'marine environmental approach to management'. This fresh approach challenges the limited, boundary- or frontier-driven approach to management by taking the nature and needs of the marine environment as a starting point for asking questions about the most appropriate forms of marine environmental management. It demonstrates why the 'frontier' concept, when applied to the ocean, is unhelpful and potentially counter-productive. It also shows how considering the legally mandated marine environment also as a 'creative space' could be constructive in achieving, inter alia, the objectives of initiatives such as the BвNJ negotiations. Implementing this approach entails setting up a new creative space within

75 With thanks to G Roddenberry (from the introduction to the television series Star Trek, Season 1, first broadcast on television (NBC) in the United States on 10 August 1966).

76 See, e.g., F Mathews, 'From Biodiversity-based Conservation to an Ethic of Bioproportionality' (2016) 200 Biological Conservation 140-148, DOI: 10.1016/j.biocon .2016.05.037.

77 For example, the stories of Arachne, Bellerophon, Cassiopeia, Icarus, Niobe, Orion, Phaethon, Theseus.

78 For example, Sophocles: Ajax, Oedipus Rex; Aeschylus: Agamemnon, Persae; Euripides: Bacchae; Medea.

For example, Homer: Iliad, Odyssey. 
which both boundaries and frontiers must be questioned, especially in terms of their potential to serve as barriers to effective management. They must then either be eliminated altogether or take different, more fruitful forms, no matter how politically inconvenient or logistically complex, and that are based on rigorous science. A marine environmental approach to management demands a long-term perspective, longer than that usually taken by most politicians and governments, who generally seem to think that they must respond to shortterm demands, regardless of the long-term consequences of their responses.

Singling out and privileging the protection of marine biodiversity over the protection of the marine environment is incompatible with the LOSC and with the frontier- and boundary-free physical and natural reality the LOSC recognizes and largely enables for action to protect the marine environment. The wisdom of its third preambular paragraph for the oceans was elegantly articulated nearly half a millennium ago by that creative space in human form, William Shakespeare: 'problems come not in single spies, but in battalions' ${ }^{80}$

8 Claudius to Gertrude, Hamlet, Act 4, Scene 5 ( 1599). 